Supporting Information

\title{
Group-Targeting SERS Screening of Total Benzodiazepines Based on Large-size (111) Faceted Silver Nanosheets Decorated with Zinc Oxide Nanoparticles
}

Changding Wang, ${ }^{[a]}$ Xiaohui Xu, ${ }^{[b]}$ Guoyu Qiu, ${ }^{[b]}$ Weichun Ye, ${ }^{*[a]}$ Yumin Li, ${ }^{* a]}$ Richard A. Harris $^{*}{ }^{[c]}$ and Chaoyang Jiang ${ }^{*[\mathrm{~d}]}$

[a] State Key Laboratory of Applied Organic Chemistry and Department of Chemistry and Key Laboratory of Digestive System Tumors

Lanzhou University

Lanzhou 730000, China.

E-mail: yewch@lzu.edu.cn (W. C. Ye); liym@lzu.edu.cn (Y. M. Li)

[b] Lanzhou Institutes for Food and Drug Control

Lanzhou 730000, China

[c] Department of Physics

University of the Free State

Bloemfontein, 9301, South Africa.

Email:harrisra@ufs.ac.za (R. A. Harris)

[d] Department of Chemistry and Center for Fluorinated Functional Materials

University of South Dakota

Vermillion, South Dakota 57069, United States.

E-mail: Chaoyang.Jiang@usd.edu (C. Y. Jiang) 


\section{Table of Contents}

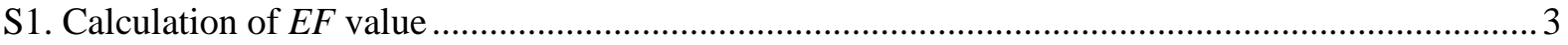

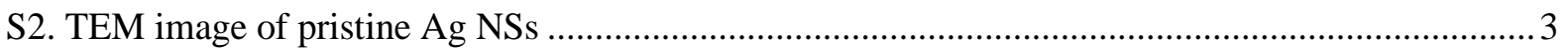

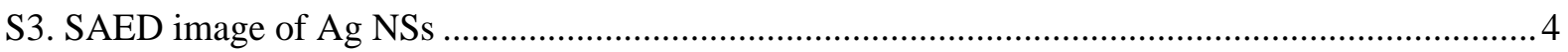

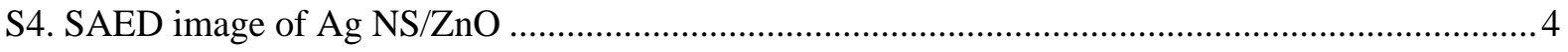

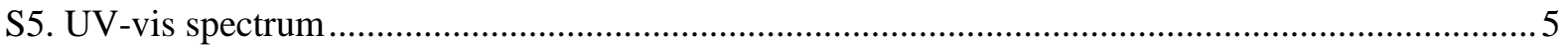

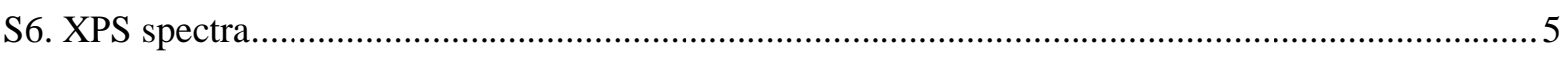

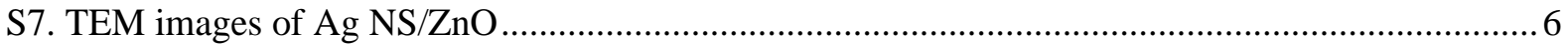

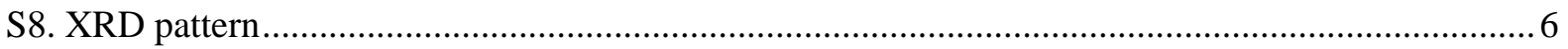

S9. TEM images of Ag NS/ZnO modified with 4-MBA ...............................................................

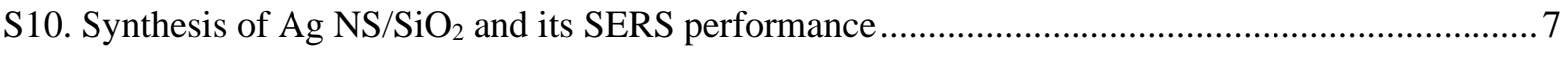

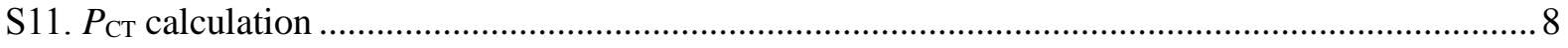

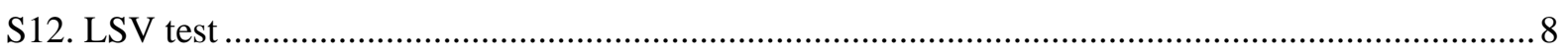

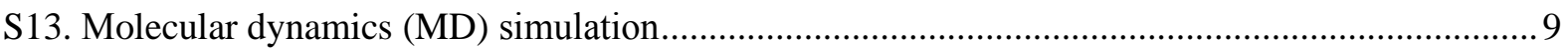

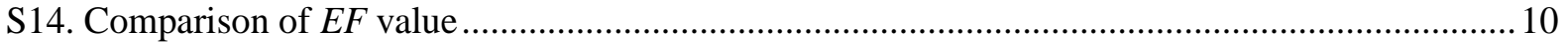

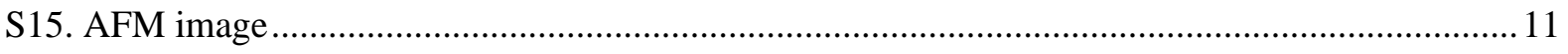

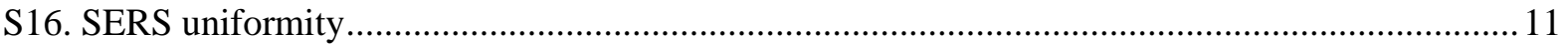

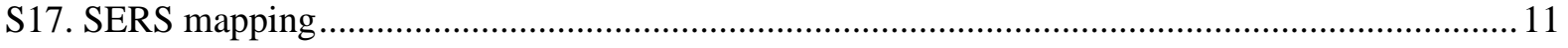

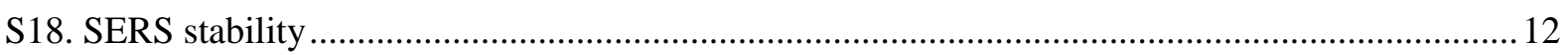

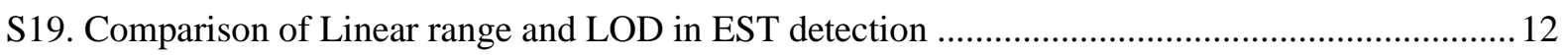

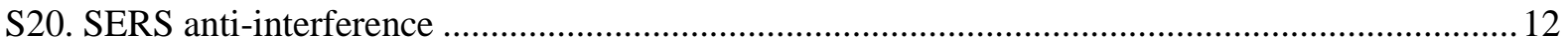

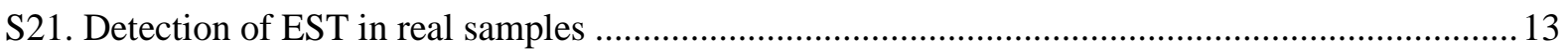

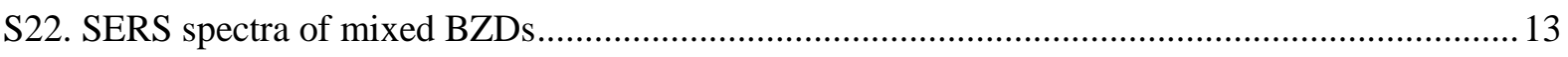

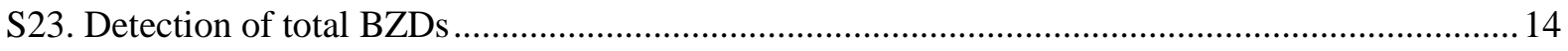

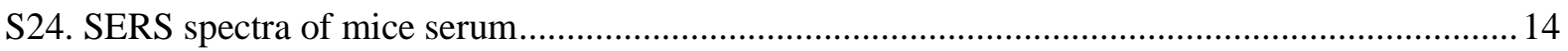

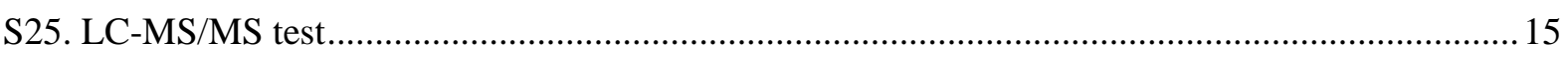

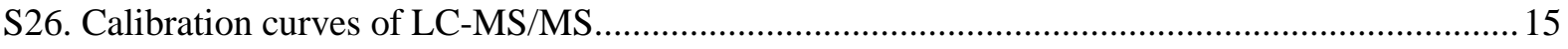

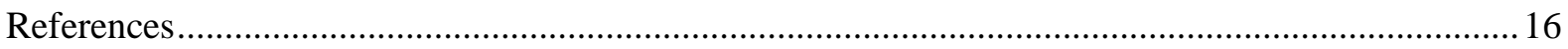




\section{S1. Calculation of $E F$ value}

The $E F$ value can be calculated by the following equation:

$$
E F=\left(I_{\text {SERS }} / I_{\text {bulk }}\right)\left(N_{\text {bulk }} / N_{\text {SERS }}\right)
$$

where $I_{\text {SERS }}$ is the intensity of the Raman spectra of the sample. $I_{\text {bulk }}$ is the Intensity of the normal Raman spectra of solid R6G. $N_{\text {bulk }}$ is the molecule number of the solid R6G in the laser illumination volume. $N_{\text {SERS }}$ is the total number of surface adsorbed molecules.

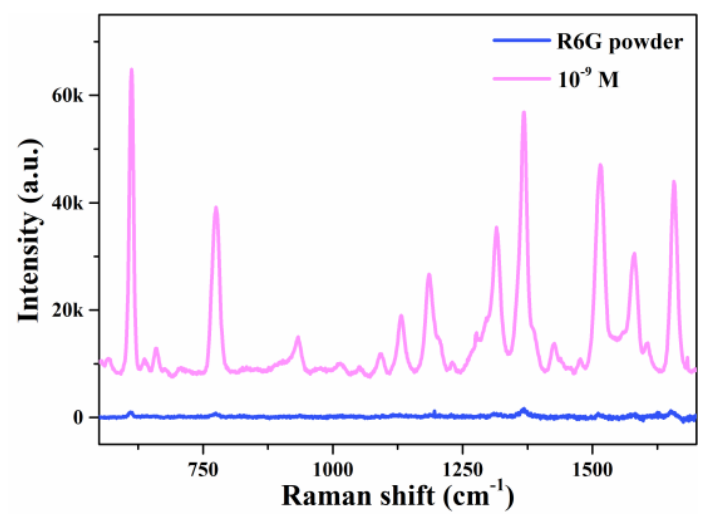

Figure S1. SERS spectrum of $10^{-9} \mathrm{M}$ R6G on Ag NS/ZnO hybrids and Raman spectrum of R6G powder

From Figure S1, taking the $613 \mathrm{~cm}^{-1}$ peak as an example, $I_{\text {bulk }}$ and $I_{\text {SERS }}$ were measured to be 948 and 54877 counts (respectively). Considering the density of solid R6G equals to $0.99 \mathrm{~g} / \mathrm{cm}^{3}, N_{\text {bulk }}$ was calculated to be about $1.95 \times 10^{9}$ under the illumination of laser light. Herein, the laser spot of $1 \mu \mathrm{m}$ diameter and the penetration depth $(\sim 2 \mu \mathrm{m})$ of the focused laser beam were used. Thus, the contact area of R6G was 12.5 $\mathrm{mm}^{2}$. The volume of R6G solution was $25 \mu \mathrm{L}$. Within the illuminated laser spot, $N_{\mathrm{SERS}}$ can be calculated as follows:

$$
N_{\mathrm{SERS}}=N_{\mathrm{A}} \times 0.25 \pi \mu \mathrm{m}^{2} \times\left(25 \mu \mathrm{L} \times 10^{-9} \mathrm{M}\right) /\left(12.5 \mathrm{~mm}^{2}\right)=945.14
$$

Thus, the $E F$ value $@ 613 \mathrm{~cm}^{-1}$ was calculated to be $1.19 \times 10^{8}$.

\section{S2. TEM image of pristine Ag NSs}

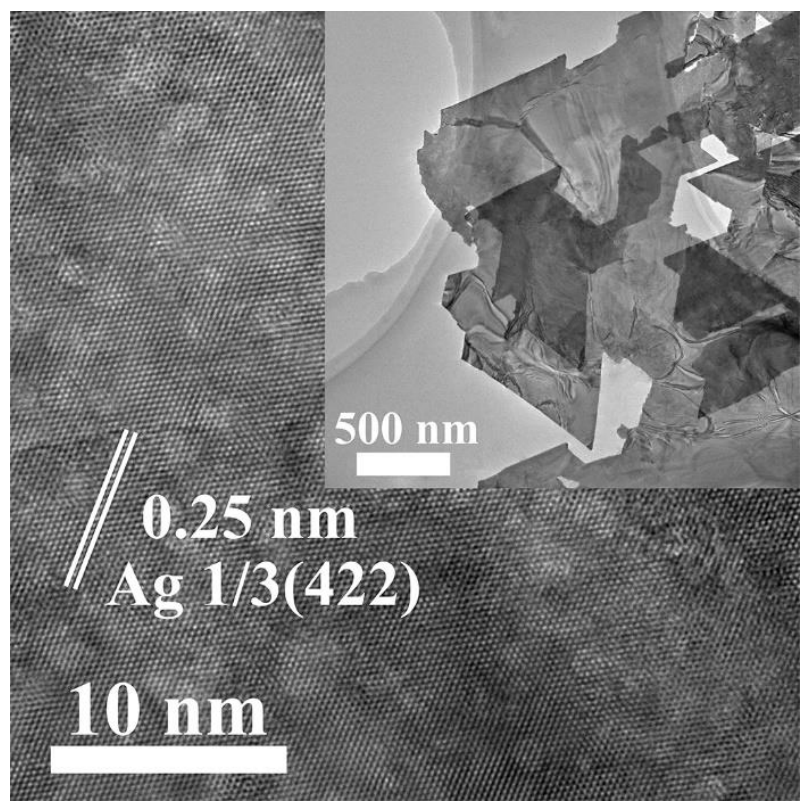

Figure S2. HRTEM and TEM (the inset) images of pristine Ag NSs. 


\section{S3. SAED image of Ag NSs}

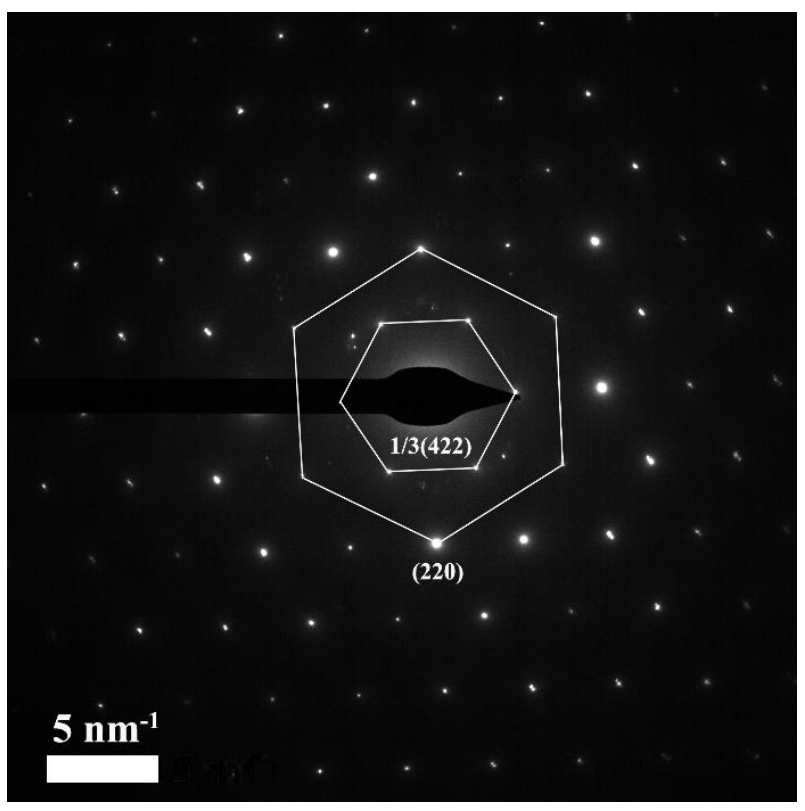

Figure S3. SAED pattern of Ag NSs.

\section{S4. SAED image of $\mathrm{Ag} \mathrm{NS/ZnO}$}

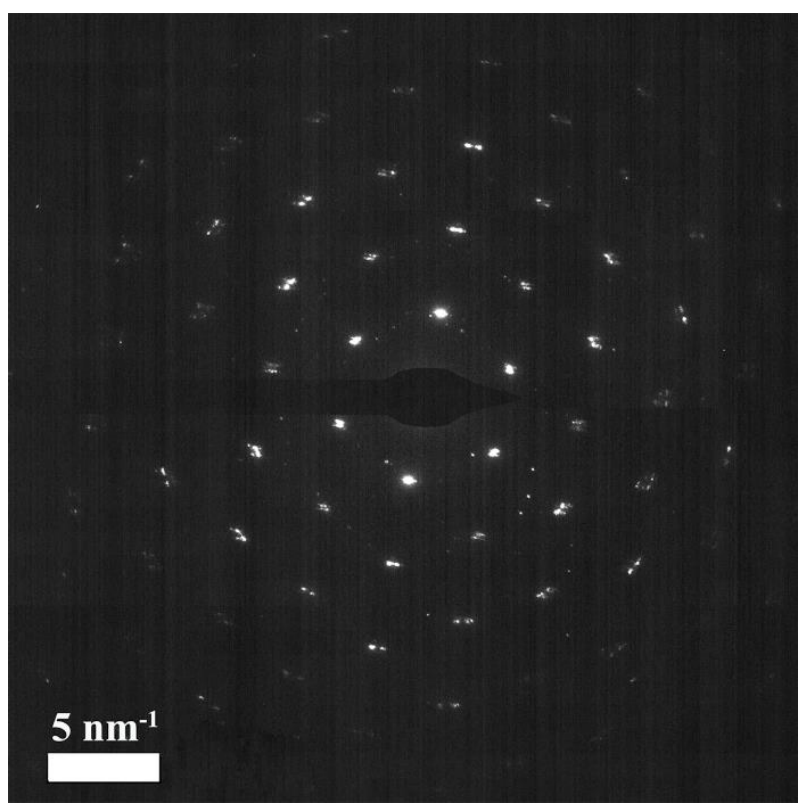

Figure S4. SAED pattern of Ag NS/ZnO. 


\section{S5. UV-vis spectrum}

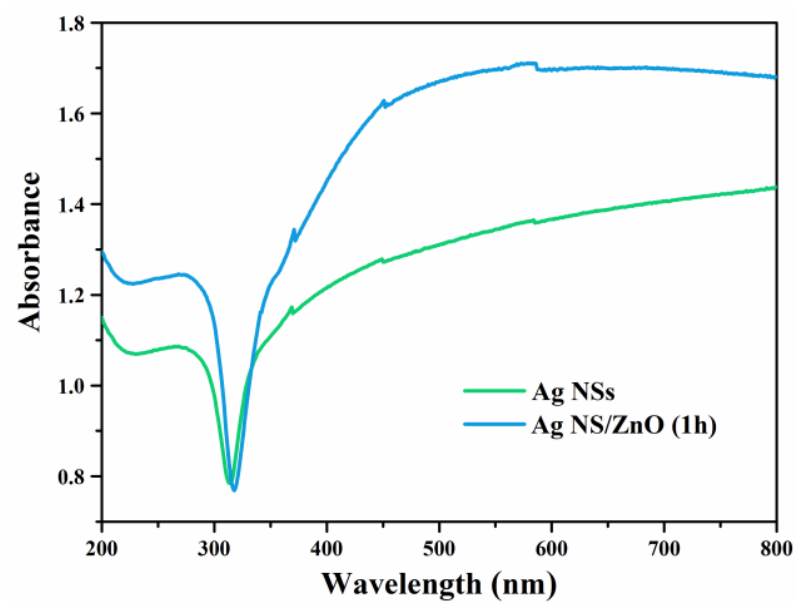

Figure S5. UV-vis absorption spectrum of the Ag NS/ZnO which were dispersed in water.

\section{S6. XPS spectra}
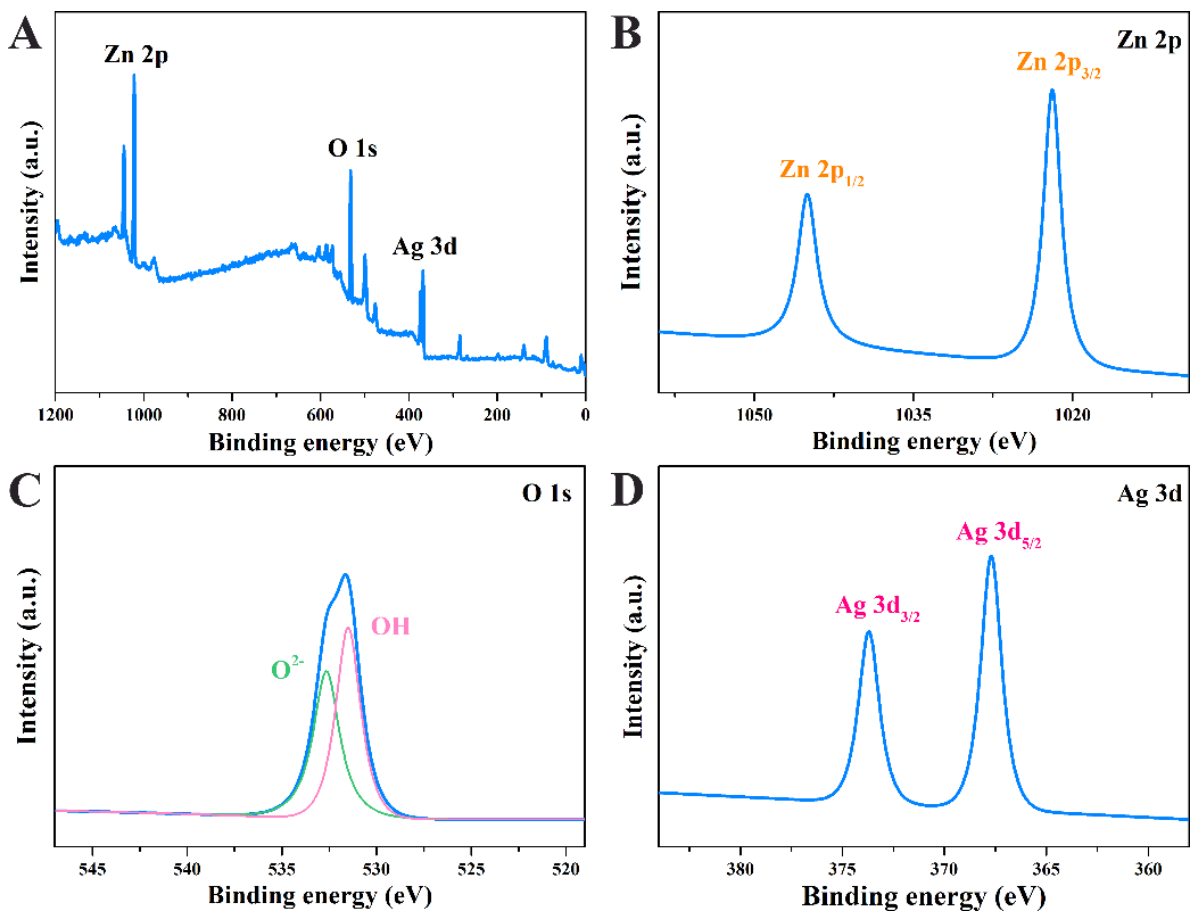

Figure S6. XPS spectra of Ag NS/ZnO hybrids: (A) Survey spectrum; (B) Zn 2p; (C) O 1s and (D) Ag 3d.

Figure S6B shows the $\mathrm{Zn} 2 \mathrm{p}$ BEs, in which $\mathrm{Zn} 2 \mathrm{p}_{3 / 2}$ and $\mathrm{Zn} 2 \mathrm{p}_{1 / 2}$ are observed at 1021.91 and $1044.99 \mathrm{eV}$, respectively. This indicates that $\mathrm{Zn}$ mainly presents in the chemical state of $\mathrm{Zn}^{2+}$. 

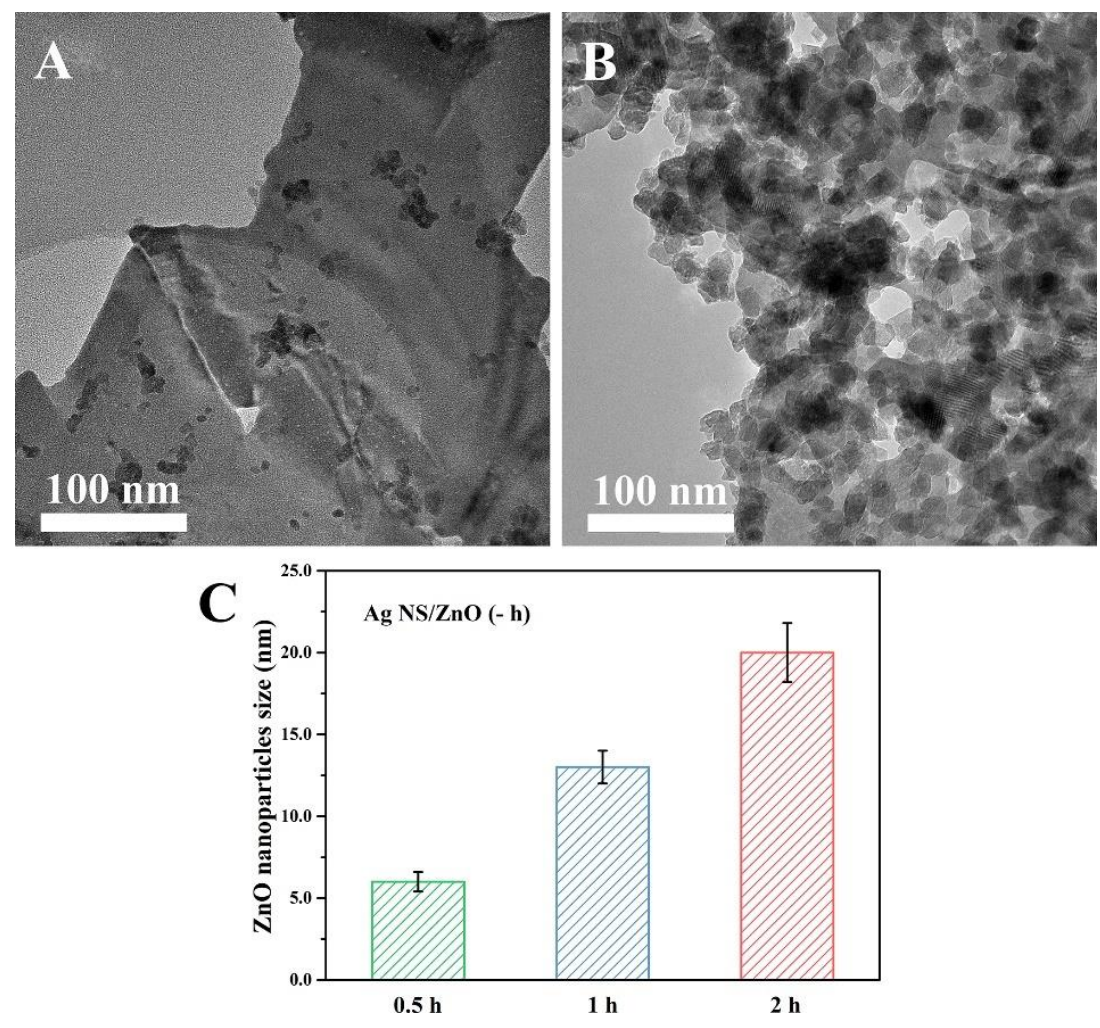

Figure S7. TEM images of Ag NS/ZnO (0.5 h) (A) and Ag NS/ZnO (2 h) hybrids (B); (C) Bar graph for the average ZnO particle size corresponding to the $\mathrm{Ag} \mathrm{NS} / \mathrm{ZnO}$ hybrids.

\section{S8. XRD pattern}

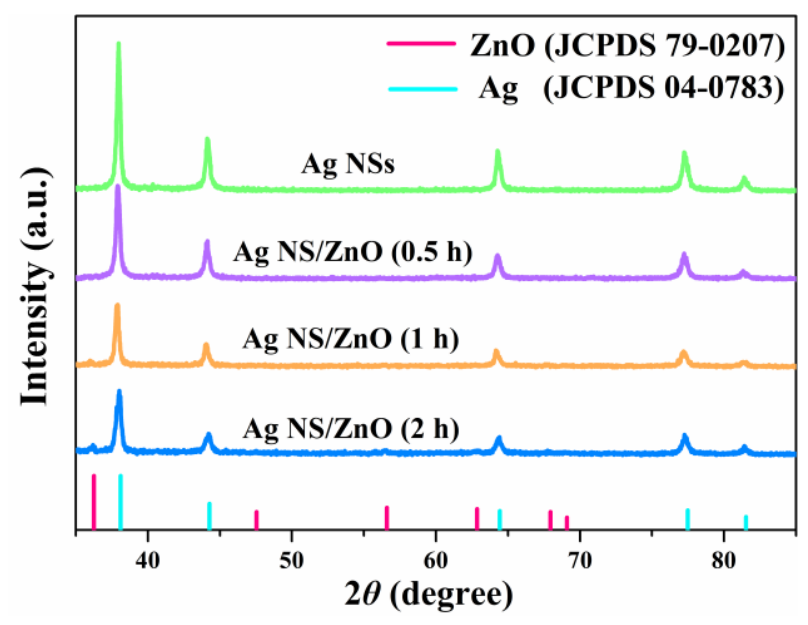

Figure S8. XRD patterns for Ag NSs and Ag NS/ZnO hybrids.

Figure S8 shows the XRD patterns of pure large-size Ag NSs and the Ag NS/ZnO hybrids with different $\mathrm{ZnO}$ growth time. The $\mathrm{Ag} f c c$ crystalline phase can be clearly seen in all the patterns, according to the characteristic diffraction peaks at $2 \theta=38^{\circ}(111), 44^{\circ}(200), 69^{\circ}(220)$, and $81^{\circ}$ (311) (JCPDS card No. 040783). 


\section{S9. TEM images of Ag NS/ZnO modified with 4-MBA}
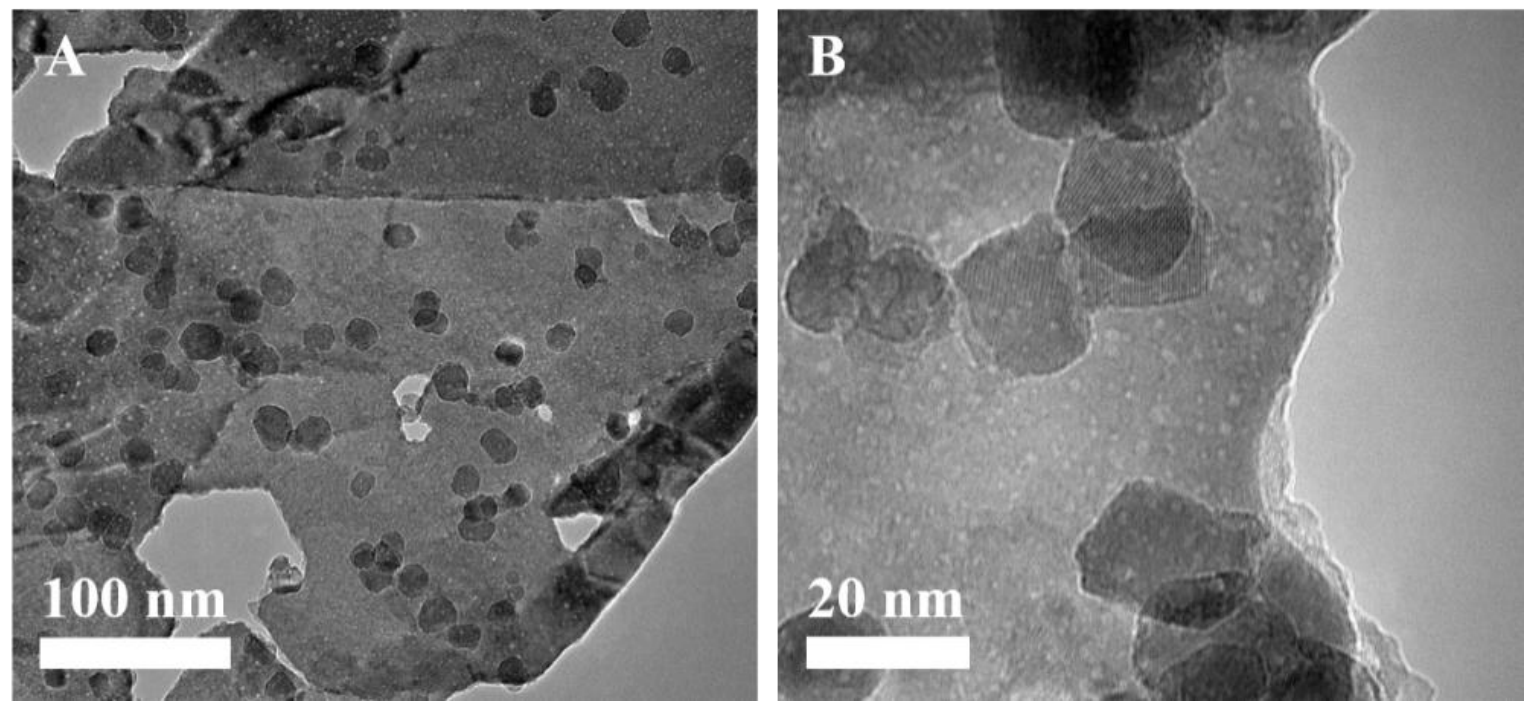

Figure S9. TEM images of Ag NS/ZnO (1 h) hybrids modified with 4-MBA (A and B).

\section{S10. Synthesis of $\mathrm{Ag} \mathrm{NS/SiO}$ and its SERS performance}

Cabbage-like (111) faceted Ag NSs were firstly synthesized according to our reported method. ${ }^{1}$ The reaction product was ultrasonic in water and then precipitated with centrifugation ( $8000 \mathrm{rmp}, 10 \mathrm{~min})$. The precipitate was then vacuum dried at $60^{\circ} \mathrm{C}$ to obtain large-size $\mathrm{Ag} \mathrm{NSs}$. To make the $\mathrm{Ag} \mathrm{NS} / \mathrm{SiO}_{2}$ hybrids, add $10 \mathrm{~mL}$ of ethanol and $100 \mu \mathrm{L}$ of ammonia to $50 \mathrm{~mL}$ of water, and then mixed with $50 \mathrm{mg}$ of the assynthesized Ag NSs to form a uniform dispersion. $100 \mu \mathrm{L}$ ethyl silicate was added to the dispersion drop by drop, and then heated to $25^{\circ} \mathrm{C}$ under stirring. The reaction was maintained at $25^{\circ} \mathrm{C}$ for a desired time $(10 \mathrm{~min}$, $0.5 \mathrm{~h}$ and $1 \mathrm{~h}$ ). The final product (the $\mathrm{Ag} \mathrm{NS} / \mathrm{SiO}_{2}$ hybrids) was collected by centrifugation and washed with water and ethanol.

The Ag NS/SiO 2 hybrids with different $\mathrm{SiO}_{2}$ content were soaked in a 4-MBA ethanol solution $\left(10^{-3} \mathrm{M}\right)$ for overnight. The hybrids were then transferred to clean silicon wafers and studied in the Raman system. The SERS results are shown in Figure S10.
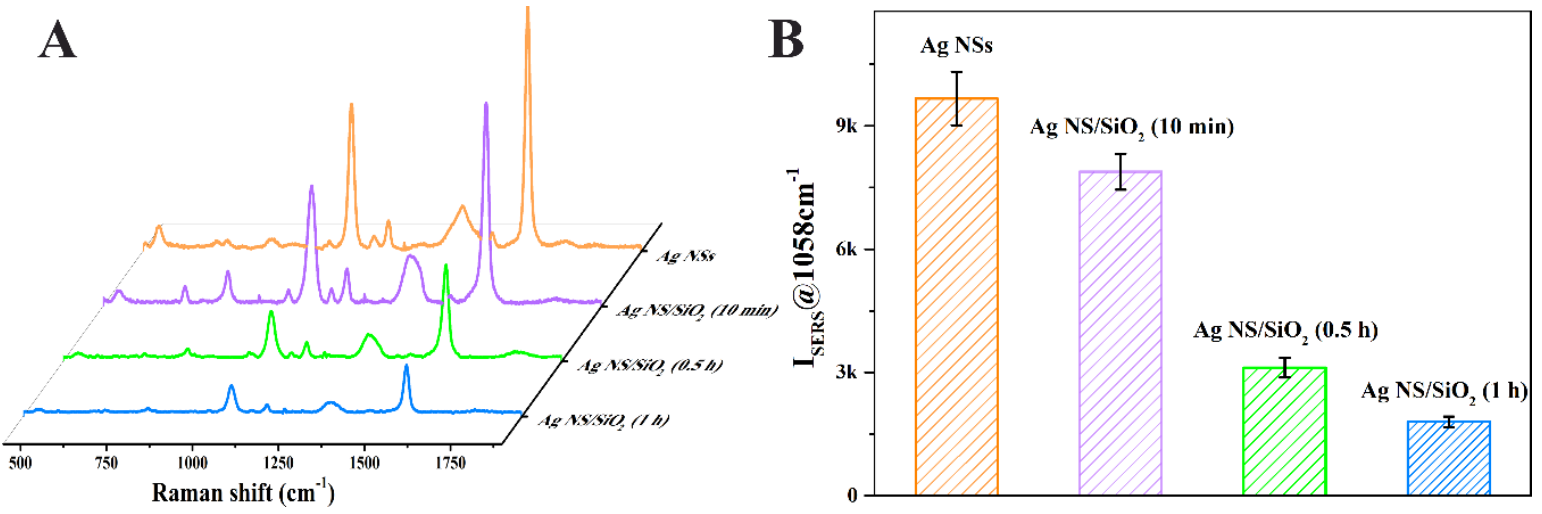

Figure S10. SERS spectra (A) and peak intensity @ $1058 \mathrm{~cm}^{-1}$ (B) of $1 \mathrm{mM} 4-\mathrm{MBA}$ adsorbed on pure $\mathrm{Ag} \mathrm{NSs}$ and $\mathrm{Ag} \mathrm{NS} / \mathrm{SiO}_{2}$ hybrids. 


\section{S11. $P_{\mathrm{CT}}$ calculation}

The $P_{\mathrm{CT}}$ value is introduced and calculated as follows: ${ }^{1,2}$

$$
P_{C T}(k)=\frac{I^{k}(C T)-I^{k}(S P R)}{I^{k}(C T)+I^{0}(S P R)}
$$

where $I^{\mathrm{k}}(\mathrm{CT})$ is the intensity of individual molecular bands of $\mathrm{CT}$ resonance in the spectral region; two bands with no CT contribution are selected as a reference: one is $I^{k}(\mathrm{SPR})$, the intensity of the band only from SPR contributes; the other is a totally symmetric band, called $I^{0}(\mathrm{SPR}) . I^{\mathrm{k}}(\mathrm{SPR})$ is generally close to zero. ${ }^{3}$

In this study, the peak at $1127 \mathrm{~cm}^{-1}$ is assigned to $b_{2}$ vibration mode and its intensity stands for $I^{\mathrm{k}}(\mathrm{CT})$. The peak intensity at $1166 \mathrm{~cm}^{-1}\left(a_{1}\right.$ mode) is selected as $I^{0}(\mathrm{SPR})$.

Table S1. Parameters for calculating $P_{\mathrm{CT}}$ value.

\begin{tabular}{cccc}
\hline Material & $I^{\mathrm{k}}(\mathrm{CT})$ & $I^{0}(\mathrm{SPR})$ & $P_{\text {CT }}$ \\
\hline Ag NSs & 734 & 1697 & 0.30 \\
Ag NS/ZnO (0.5h) & 1902 & 3041 & 0.38 \\
Ag NS/ZnO (1h) & 4277 & 5545 & 0.44 \\
Ag NS/ZnO (1.5h) & 1371 & 2457 & 0.36 \\
Ag NS/ZnO (2h) & 515 & 1156 & 0.31 \\
\hline
\end{tabular}

\section{S12. LSV test}

Line sweep voltammograms (LSVs) was recorded on a CHI 660C electrochemical workstation (Chenhua, Shanghai China). A $500 \mathrm{~W}$ xenon lamp (CHF-XM-500 W, Beijing Trusttech Co. Ltd.) with a $420 \mathrm{~nm}$ cutoff filter $(\lambda>420 \mathrm{~nm}$ ) was used. A three-electrode photoelectrochemical (PEC) cell was applied to evaluate the photoresponse properties in $0.1 \mathrm{M} \mathrm{Na}_{2} \mathrm{SO}_{4}$ electrolyte solution. Fluorine-doped tin oxide (FTO) glass modified with the $\mathrm{Ag} \mathrm{NSs} / \mathrm{ZnO}$ hybrids, $\mathrm{Ag} / \mathrm{AgCl}$ and a Pt wire were used as the working, reference and counter electrodes, respectively. The applied potentials scanned from -0.10 to $0.25 \mathrm{~V}$. Scan rate was $10 \mathrm{mV} / \mathrm{s}$.

Prior to the measurement, FTO glass was ultrasonically cleaned by ethanol, acetone, and deionized water for three times, and dried with $\mathrm{N}_{2}$. The $\mathrm{Ag} \mathrm{NS} / \mathrm{ZnO}$ hybrids were dispersed in water containing $0.1 \mathrm{wt} \%$ Nafion to form a uniform suspension. $50 \mu \mathrm{L}$ suspension was put on the FTO surface $\left(1 \times 1 \mathrm{~cm}^{2}\right)$ uniformly and dried with $\mathrm{N}_{2}$.

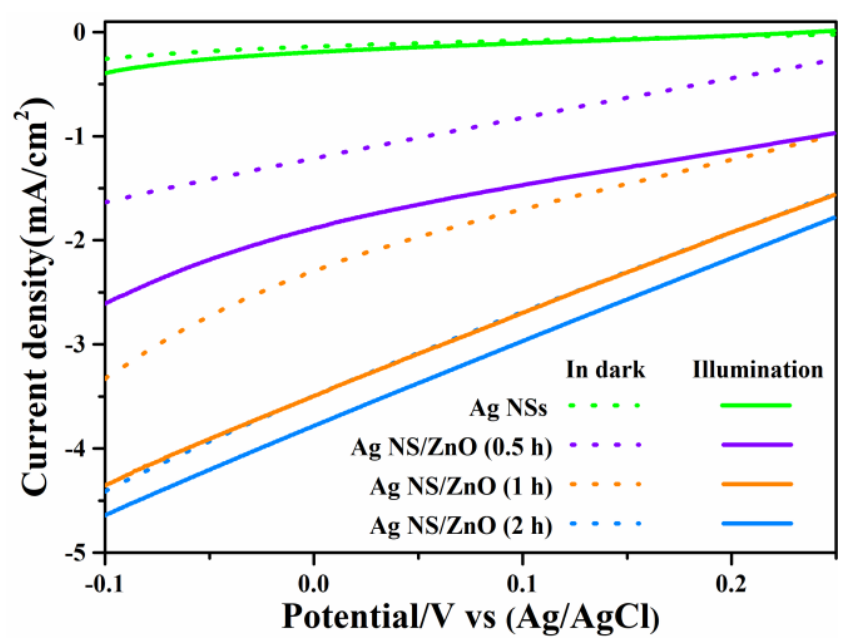

Figure S11. LSVs in 0.1 M Na2 $\mathrm{SO}_{4}$ solution under illumination or in dark over different materials modified on FTO. Scan rate was $10 \mathrm{mV} / \mathrm{s}$. The solid and dot lines stand for the illumination and dark conditions, respectively. 


\section{S13. Molecular dynamics (MD) simulation}

To perform MD simulations, a similar method as reported in literature ${ }^{2-4}$ was used. Briefly: truncated octahedral $\mathrm{ZnO}$ nanocrystals of $2.8 \mathrm{~nm}$ were constructed with an $\mathrm{Ag}$ supercell-surface. The $\mathrm{ZnO}$ NPs were manually deposited onto the Ag surface and geometrically and energetically optimized. A constant number of $\mathrm{ZnO}$ NPs were used (16) and the inter-particle distance was varied by adjusting the inter-particle distance. Ten systems were simulated (A to J), ranging from system A with a NPs density of $0.123 \mathrm{NPs} / \mathrm{nm}^{2}$ with a 2 $\AA$ separation between the particles, to J, $0.057 \mathrm{NPs} / \mathrm{nm}^{2}$ with a $2 \mathrm{~nm}$ separation between NPs. The BE as a function of $\mathrm{ZnO} \mathrm{NP}$ density for the systems can be seen in the context.

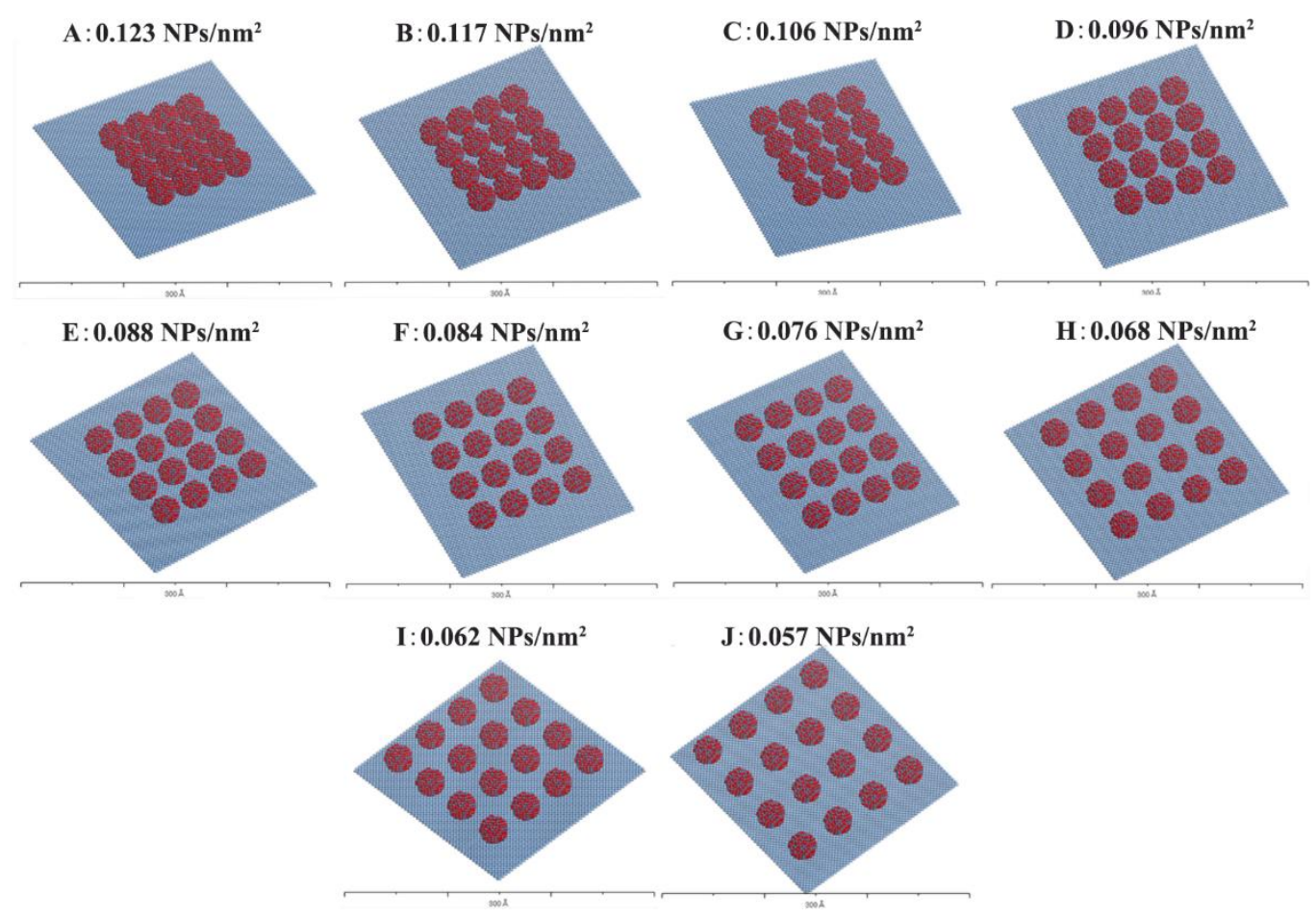

Figure S12. Hybrid Ag NS/ZnO systems with varying NPs densities ranging from $0.123 \mathrm{NPs} / \mathrm{nm}^{2}$ to $0.057 \mathrm{NPs} / \mathrm{nm}^{2}$.

In the simulation experiment, the molecules were allowed to interact with both the $\mathrm{ZnO}$ NPs as well as the Ag NSs. This was done in order to investigate the influence on the BE in the Ag NS/ZnO hybrid systems. This was done as follows. A constant number of 4-MBA molecules (260) were sequentially adsorbed onto each ZnO-Ag hybrid system via a simulated annealing Monte Carlo scheme (with restrictions applied as discussed). Molecular mechanics (MM) were used to determine the optimum geometries for each of the resulting hybrid systems. The polymer consistent valence forcefield ( $p c f f$ ) was used with charges assigned by the forcefield. These settings were applied to both Van der Waals and Coulomb forces and the summation method was atom based. The minimization method was selected as 'smart', which uses combinations of the steepest descent, conjugate gradient and newton methods. For the conjugate gradient method, the FletcherReeves algorithm was used and for the newton method the Broyden-Fletcher-Goldfarb- Shanno (BFGS) algorithm was used. 


\section{Discussion}

Another important variable determining the $\mathrm{CT}$ effect is the number of 4-MBA molecules bound to $\mathrm{ZnO}$, i.e., the density of adsorbed molecules. As a consequence of the ZnO NPs density decreasing and gaps opening up between the ZnO NPs, the number of 4-MBA molecules interacting with the ZnO NPs reduces (as the number of molecules interacting with the Ag NSs increases). Competition between the ZnO NPs and $\mathrm{Ag}$ NSs now becomes important in deciding when the molecule would rather bind to $\mathrm{ZnO}$ or Ag or both simultaneously. Since the 4-MBA molecule is prone to both nucleophilic and electrophilic attack through its oxygen atoms and the sulfur atom (which are on opposite sides of the molecule), it is self-evident that the optimum configuration would be where both the $\mathrm{S}$ and $\mathrm{O}$ atoms are electrostatically pacified which leads to a reduction in the energetics of the system. Thus, if the gaps between $\mathrm{ZnO}$ NPs are too large, a majority of molecules would interact between the gaps with the Ag NSs, leaving dangling bonds on the molecule. The same is true if the NPs density is too large: most of the molecules interact with the ZnO NPs and consequently one side of the molecule remains electrostatically unsatisfied. Optimally, when the gap size is just right, some molecules may enter the gap to interact with both the underlying Ag NSs as well as the ZnO NPs. Thus, at an optimum particle density of $0.106 / \mathrm{nm}^{2}$, the $\mathrm{BE}$ is at a maximum and slightly higher (indicative of more firm bonding) since the gap size satisfies these conditions. Consequently, the synergistic interaction between Ag NSs, ZnO NPs and 4-MBA molecules would lead to an optimized plasmonic behavior since the number of pathways for electron acceptance has increased.

\section{S14. Comparison of $E F$ value}

Table S2. Comparison of the $E F$ values with previously reported pure Ag NSs and other Ag-based substrates.

\begin{tabular}{ccc}
\hline Substrate & $E F$ & Ref. \\
\hline Pure Ag NSs & $3.56 \times 10^{6}$ & 1 \\
AgNP@ AgNW PDMS & $2.50 \times 10^{7}$ & 7 \\
3D Ag butterfly wing arrays/ graphene composites & $4.79 \times 10^{6}$ & 9 \\
ZnO/Ag nanorods & $1.98 \times 10^{7}$ & 10 \\
Ag@ZnO nanorods & $1.60 \times 10^{6}$ & 11 \\
Hydrogenated ZnO/ AgNPs & $4.90 \times 10^{7}$ & 12 \\
Mg-doped ZnO-AgNPs & $1.36 \times 10^{7}$ & 13 \\
Ag-NP-decorated ZnO nanoflower array & $4.00 \times 10^{7}$ & 14 \\
Ag/ZnO heterostructure & $5.40 \times 10^{7}$ & 15 \\
Ag/graphene oxide/TiO 2 nanorod array & $5.86 \times 10^{5}$ & 16 \\
Hollow sea urchin-like TiO $@$ Ag nanoparticle & $7.60 \times 10^{6}$ & 17 \\
Electrospun TiO $/$ Ag nanofelt & $5.62 \times 10^{6}$ & $1.19 \times 10^{8}$ \\
Ag NS/ZnO hybrids & & This work \\
\hline
\end{tabular}




\section{S15. AFM image}
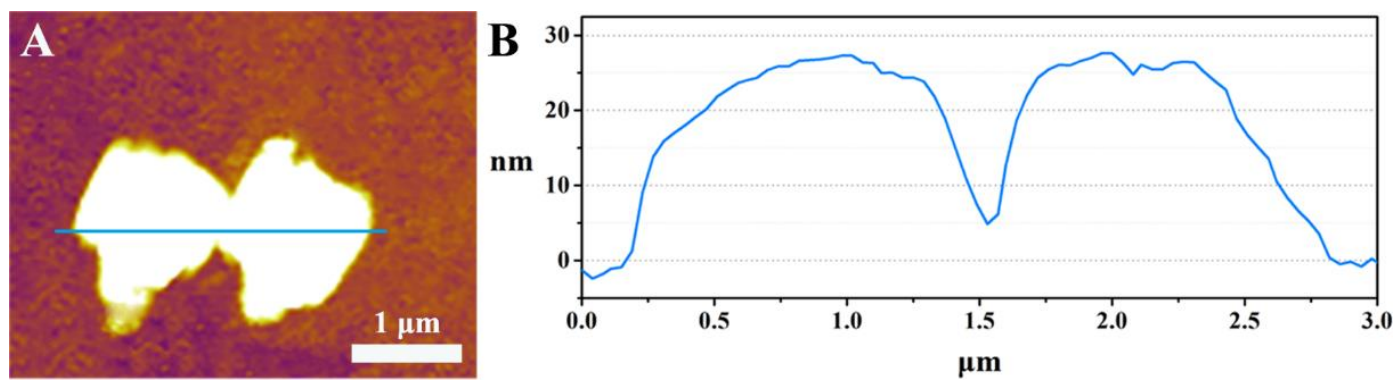

Figure S13. AFM image (A) and line width (B) of Ag NS/ZnO.

AFM measurement was performed using an atomic force microscopy (Asylum Research, MFP-3D, USA). The surface roughness of the flat surface was calculated to be $3.6 \mathrm{~nm}$ by using Asylum Research software.

\section{S16. SERS uniformity}
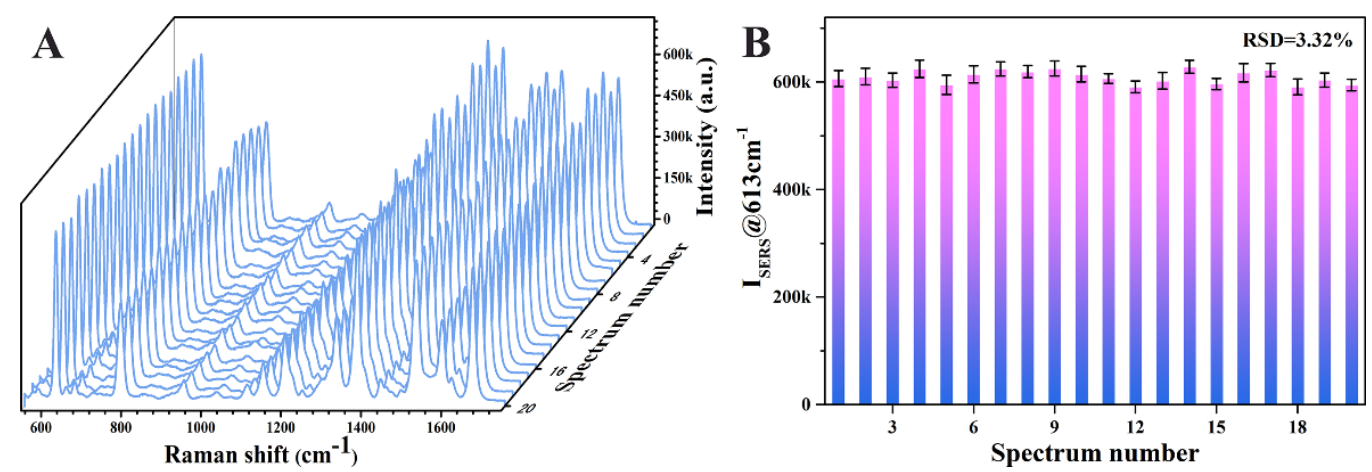

Figure S14. SERS spectra (A) and uniformity (B) of $10^{-6} \mathrm{M}$ R6G on $\mathrm{Ag} \mathrm{NS} / \mathrm{ZnO}$ at twenty random positions.

\section{S17. SERS mapping}
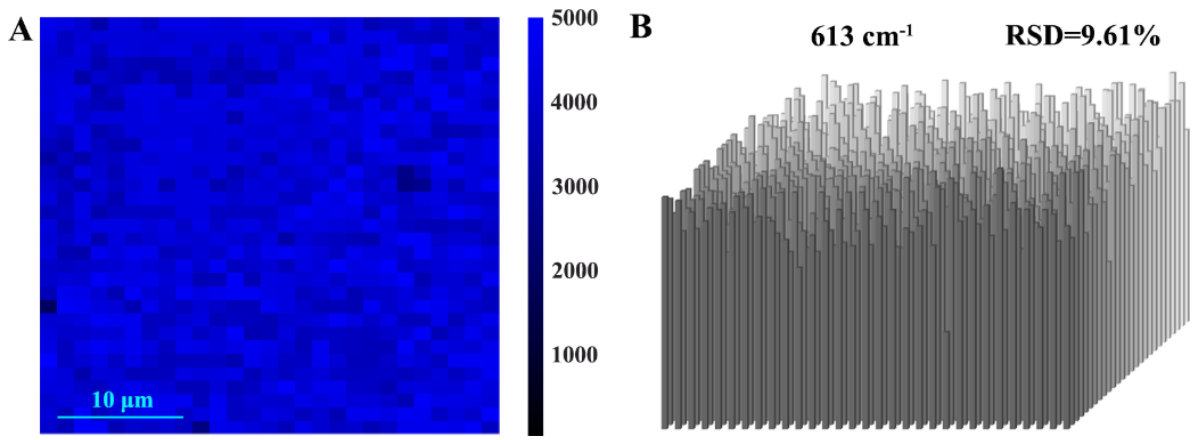

Figure S15. (A) SERS map of R6G at $613 \mathrm{~cm}^{-1}$; and corresponding histograms (B) for the above mapping area.

Raman mapping spectra was obtained by using a Renishaw inVia Raman microscope with a 600 lines/mm grating and a $514 \mathrm{~nm}$ laser. The incident laser beam was focused by a $50 \times$ objective and the laser power on the samples was kept $0.5 \mathrm{~mW}$ to avoid laser induced heating. 
S18. SERS stability
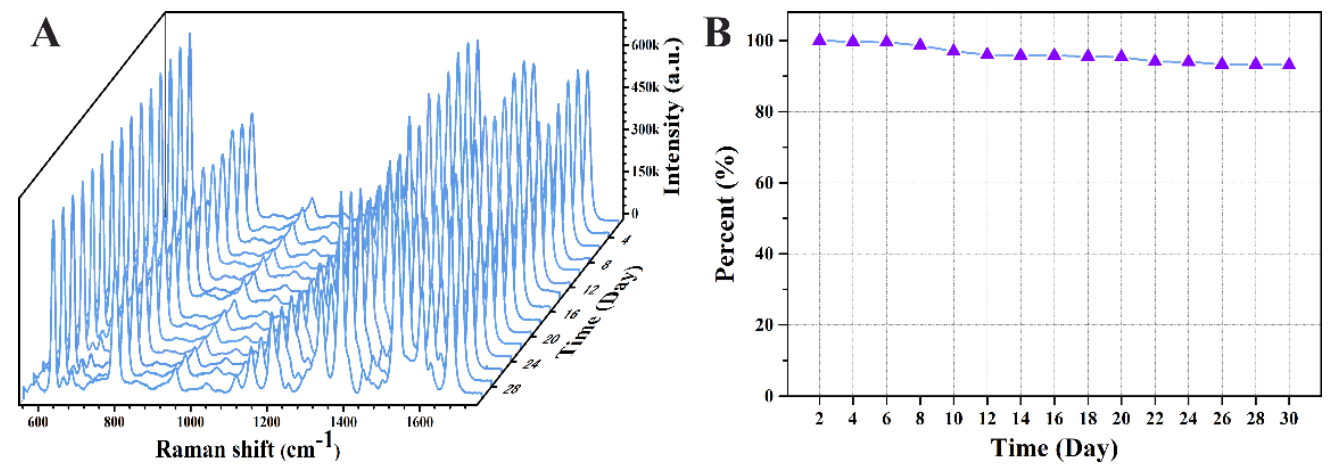

Figure S16. SERS spectra (A) and Long-term stability (B) of $10^{-6} \mathrm{M}$ R6G on Ag NS/ZnO measured every two days during one month at the room temperature.

\section{S19. Comparison of Linear range and LOD in EST detection}

Table S3. Comparison of the analytic performance for EST detection between this SERS substrate and the previous work with other analytic methods.

\begin{tabular}{cccc}
\hline Method & Linear range $(\mathrm{M})$ & LOD $(\mathrm{M})$ & Ref. \\
\hline HPLC $^{\mathrm{a}}$ & $3.39 \times 10^{-9}-6.79 \times 10^{-7}$ & $1.68 \times 10^{-9}$ & 18 \\
Electrochemistry $^{-9}$ & $10^{-7}-9.00 \times 10^{-6}$ & $5.00 \times 10^{-8}$ & 19 \\
ic-ELISA $^{\mathrm{b}}$ & $1.27 \times 10^{7}-2.04 \times 10^{-6}$ & $2.04 \times 10^{-6}$ & 20 \\
GC-TOF-MS $^{\mathrm{c}}$ & $2.71 \times 10^{8}-1.19 \times 10^{-6}$ & $6.11 \times 10^{-9}$ & 21 \\
HILIC $^{\mathrm{d}}$ & $8.48 \times 10^{8}-3.39 \times 10^{-6}$ & $3.39 \times 10^{-8}$ & 22 \\
SPE$/ G C-M S^{\mathrm{e}}$ & $6.79 \times 10^{8}-3.39 \times 10^{-6}$ & $1.70 \times 10^{-8}$ & 23 \\
SERS & $10^{-9}-10^{-3}$ & $5.00 \times 10^{-10}$ & This work \\
\hline
\end{tabular}

${ }^{a}$ High-performance liquid chromatography (HPLC)

${ }^{\mathrm{b}}$ Indirect competitive enzyme-linked immunosorbent assay (ic-ELISA)

${ }^{c}$ Gas chromatography-time-of-flight mass spectrometry (GC-TOF-MS)

${ }^{\mathrm{d}}$ Hydrophilic interaction chromatography (HILIC)

${ }^{\mathrm{e}}$ Solid-phase extraction and gas chromatography-mass spectrometry (SPE/GC-MS)

S20. SERS anti-interference
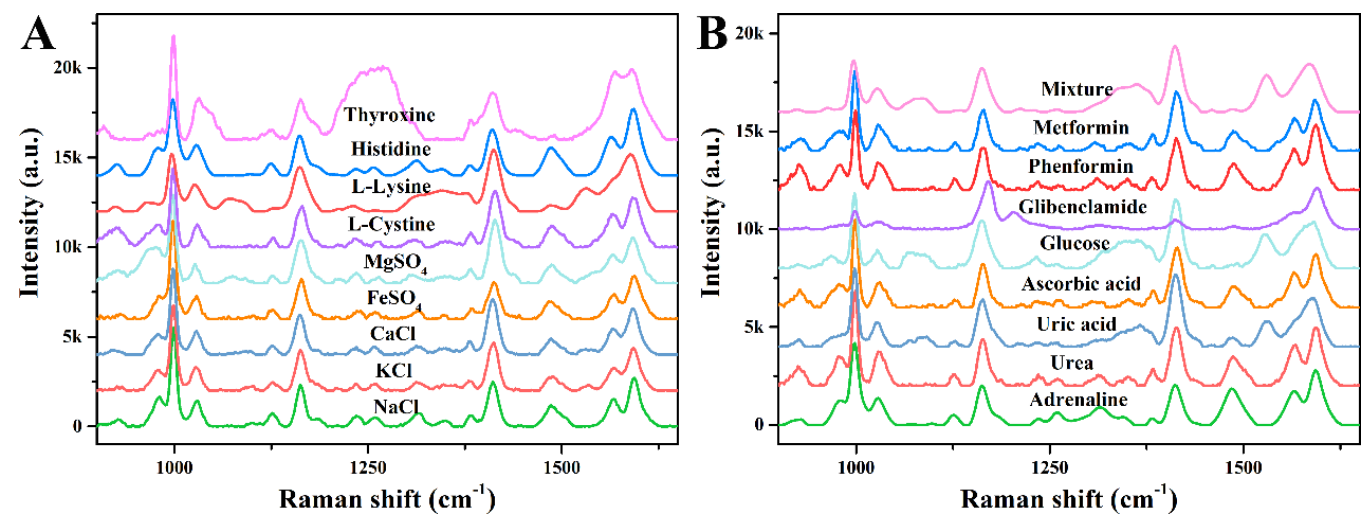

Figure S17. SERS spectra of $1.0 \mu \mathrm{M}$ EST solution with various interfering species $(0.1 \mathrm{mM})$ on $\mathrm{Ag} \mathrm{NS} / \mathrm{ZnO}$ hybrids, include (A) inorganic salts, amino acids and derivative; and (B) organic compounds, drugs, and amino acid derivative. 


\section{S21. Detection of EST in real samples}

Table S4. Detection of EST in FBS and urine samples based on Ag NS/ZnO hybrids $(n=5)$.

\begin{tabular}{cccccc}
\hline Sample & Original $(\mu \mathrm{M})$ & Spiked $(\mu \mathrm{M})$ & Found $(\mu \mathrm{M})$ & Recovery $(\%)$ & RSD $(\%)$ \\
\hline \multirow{3}{*}{ FBS } & \multirow{3}{*}{ No found } & 5.00 & 4.60 & 92.00 & 2.86 \\
& & 1.00 & 0.91 & 91.00 & 3.34 \\
& & 0.50 & 0.47 & 94.00 & 2.95 \\
\multirow{3}{*}{ Urine } & 5.00 & 5.13 & 102.60 & 3.71 \\
& \multirow{3}{*}{ No found } & 1.00 & 0.94 & 94.00 & 2.28 \\
& & 0.50 & 0.51 & 102.00 & 3.30 \\
\hline
\end{tabular}

\section{S22. SERS spectra of mixed BZDs}
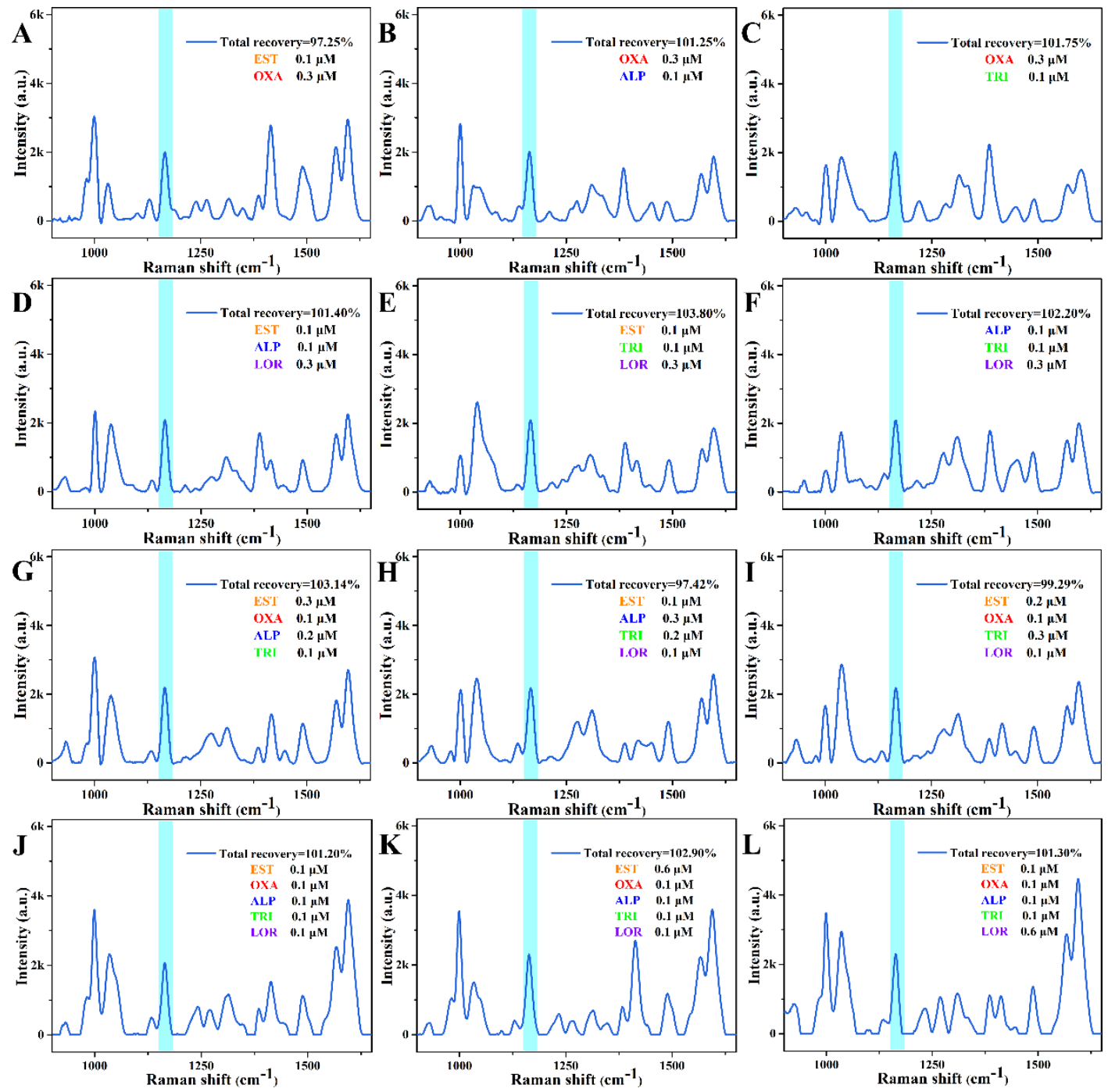

Figure S18. SERS spectra of BZD mixtures (A-L) with different ratios of individual BZDs on Ag NS/ZnO hybrids. The mixture compositions are labeled in each panel. 


\section{S23. Detection of total BZDs}

Table S5. Detection of total BZDs with different mixed ratios based on the EST calibration equation $(n=5)$.

\begin{tabular}{|c|c|c|c|c|c|c|c|c|}
\hline \multicolumn{5}{|c|}{ Spiked $(0.1 \mu \mathrm{M})$} & \multirow{2}{*}{ Total $(0.1 \mu \mathrm{M})$} & \multirow{2}{*}{ Found $(0.1 \mu \mathrm{M})$} & \multirow{2}{*}{ Recovery (\%) } & \multirow{2}{*}{$\operatorname{RSD}(\%)$} \\
\hline EST & OXA & ALP & TRI & LOR & & & & \\
\hline 1.00 & 1.00 & 1.00 & 1.00 & 1.00 & 5.00 & 5.06 & 101.20 & 2.90 \\
\hline 6.00 & 1.00 & 1.00 & 1.00 & 1.00 & 10.00 & 10.29 & 102.90 & 3.34 \\
\hline 1.00 & 1.00 & 1.00 & 1.00 & 6.00 & 10.00 & 10.13 & 101.30 & 4.01 \\
\hline 3.00 & 1.00 & 2.00 & 1.00 & - & 7.00 & 7.22 & 103.14 & 3.90 \\
\hline 1.00 & - & 3.00 & 2.00 & 1.00 & 7.00 & 6.81 & 97.42 & 4.22 \\
\hline 2.00 & 1.00 & - & 3.00 & 0.10 & 7.00 & 6.95 & 99.29 & 2.88 \\
\hline 1.00 & - & 1.00 & - & 3.00 & 5.00 & 5.07 & 101.40 & 3.28 \\
\hline 1.00 & - & - & 1.00 & 3.00 & 5.00 & 5.19 & 103.80 & 2.18 \\
\hline- & - & 1.00 & 1.00 & 3.00 & 5.00 & 5.11 & 102.20 & 2.59 \\
\hline 1.00 & 3.00 & - & - & - & 4.00 & 3.89 & 97.25 & 3.62 \\
\hline- & 3.00 & 1.00 & - & - & 4.00 & 4.05 & 101.25 & 2.39 \\
\hline- & 3.00 & - & 1.00 & - & 4.00 & 4.07 & 101.75 & 3.08 \\
\hline
\end{tabular}

\section{S24. SERS spectra of mice serum}

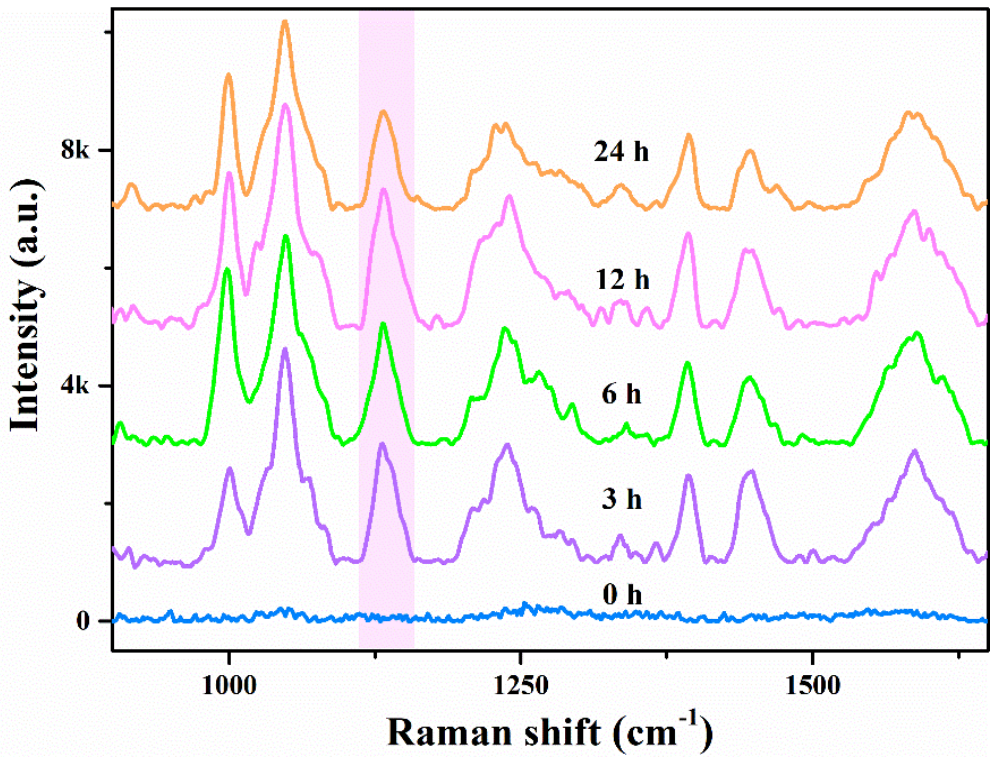

Figure S19. SERS spectra of mice serum in different sampling time on Ag NS/ZnO hybrids. 


\section{S25. LC-MS/MS test}

The chromatographic system used was an Agilent (Santa Clara, CA, USA) 1290 UHPLC. Mobile phases were consisted of aqueous solution of ammonium acetate (mobile phase A) and methanol (mobile phase B) with formic acid at $0.1 \%$. Chromatographic separation was performed on an Agilent Zorbax Eclipse Plus C18 $3.0 \times 50 \mathrm{~mm}, 1.8 \mu \mathrm{m}$ ultraperformance analytical column (Waters, Milford, MA, USA) held at $35^{\circ} \mathrm{C}$. All reagents were LC-MS grade and purchased from Aladdin (Shanghai, China).

For the BZDs assay, the column flow rate was $0.3 \mathrm{~mL} / \mathrm{min}$ without flow splitting using a gradient elution. The gradient was initiated at $30 \% \mathrm{~B}$, raised to $95 \% \mathrm{~B}$ from 0.00 to $8.00 \mathrm{~min}$, held continuous for $2.00 \mathrm{~min}$, and returned to starting conditions at $11.00 \mathrm{~min}$. The total run time was $12.00 \mathrm{~min}$.

Tandem mass spectrometric detection was performed on an Agilent (Santa Clara, CA, USA) 6460 triple quadrupole mass spectrometer with a TurboV electrospray ionization (ESI) source in positive mode. The MS parameters were optimized and determined first. A multiple reaction monitoring (MRM) mode was operated with the precursor ions $\rightarrow$ fragment ions of the analytes as follows: $\mathrm{m} / \mathrm{z} 295.1 \rightarrow 267.0$ for estazolam (collision energy, $24 \mathrm{eV}$ ); m/z $295.1 \rightarrow 192.0$ for estazolam (collision energy, $20 \mathrm{eV}$ ); m/z $287.0 \rightarrow 241.0$ for oxazepam (collision energy, $20.0 \mathrm{eV}$ ); m/z $287.0 \rightarrow 162.9$ for oxazepam (collision energy, $30.0 \mathrm{eV}$ ); m/z $321.1 \rightarrow 302.9$ for lorazepam (collision energy, $12.0 \mathrm{eV}$ ); m/z $321.1 \rightarrow 275.0$ for lorazepam (collision energy, $20.0 \mathrm{eV}$ ). Nitrogen was used for both nebulization and the sheath gas. The nebulization gas was set at $35 \mathrm{psi}$. The flow rate was $8 \mathrm{~L} / \mathrm{min}$ with the temperature set at $325^{\circ} \mathrm{C}$. The sheath gas temperature was set at $350^{\circ} \mathrm{C}$ and the flow rate was $12 \mathrm{~L} / \mathrm{min}$. Capillary voltage was set at $4000 \mathrm{~V}$ for positive mode. Nozzle voltage was set at $500 \mathrm{~V}$. High-purity nitrogen (99.999\%) was used as the collision gas.

Calibration curves were obtained by testing a series of standard concentrations of EST, LOR and OXA and plotting the peak area $v s$. the concentration of analytes (Figure S20). The total BZDs in mice serum was calculated by the calibration equation.

\section{S26. Calibration curves of LC-MS/MS}
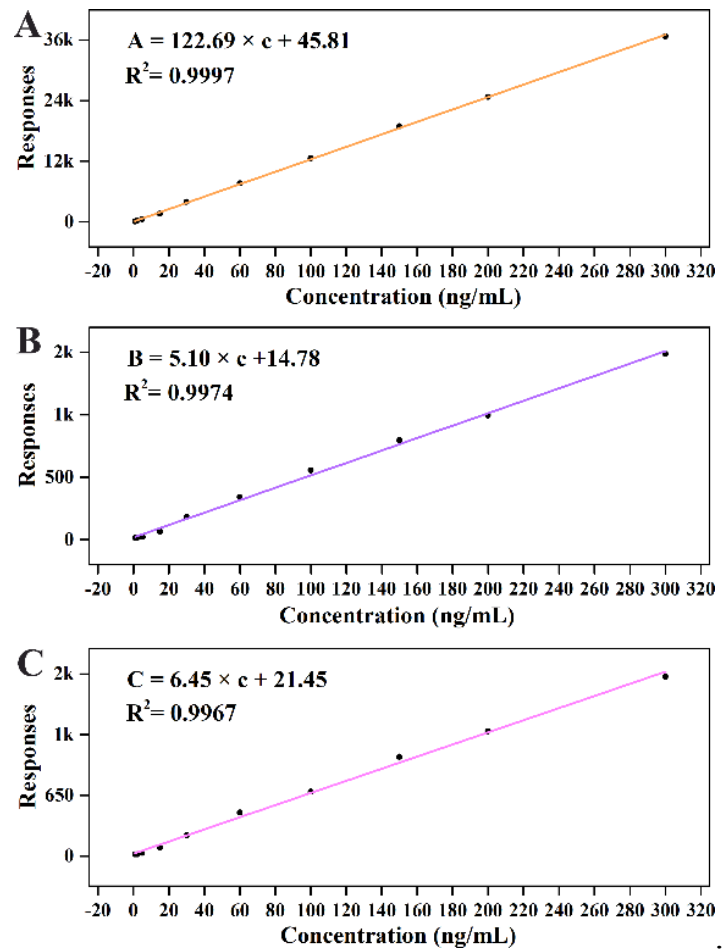

Figure S20. The relationship plots between the peak area and the (A) EST, (B) LOR and (C) OXA concentrations (respectively). 


\section{References}

(1) Liu, C.; Xu, X.; Hu, W.; Yang, X.; Zhou, P.; Qiu, G.; Ye, W.; Li, Y.; Jiang, C. Anal. Chem. 2018, 90, 9805-9812.

(2) Lombardi, J. R.; Birke, R. L. Acc. Chem. Res. 2009, 42, 734-742.

(3) Lombardi, J. R.; Birke, R. L. J. Phys. Chem. C 2008, 112, 5605-5617.

(4) Harris, R. A.; Mlambo, M.; Mdluli, P. S. RSC Adv. 2016, 6, 12131-12142.

(5) Mlambo, M.; Harris, R. A.; Mashazi, P.; Sabela, M.; Kanchi, S.; Madikizela, L. M.; Shumbula, P. N.; Moloto, N.; Hlatshwayo, T. T.; Mdluli, P. S. Appl. Surf. Sci. 2017, 396, 695-704.

(6) Prakash, J.; Kumar, P.; Harris, R.A.; Swart, C.; Neethling, J. H.; Janse van Vuuren, A.; Swart, H.C. Nanotechnology 2016, 27, 355707-355727.

(7) Wei, W.; Du, Y.; Zhang, L.; Yang, Y.; Gao, Y. J. Mater. Chem. C 2018, 6, 8793-8803.

(8) Zhang, M.; Meng, J.; Wang, D.; Tang, Q.; Chen, T.; Rong, S.; Liu, J.; Wu, Y. J. Mater. Chem. C 2018, 6, 1933-1943.

(9) Liu, C.; Xu, X.; Wang, C.; Qiu, G.; Ye, W.; Li, Y.; Wang, D. Sens. Actuat. B-Chem. 2020, 307, 127634.

(10) Macias-Montero, M.; Pelaez, R. J.; Rico, V. J.; Saghi, Z.; Midgley, P.; Afonso, C. N.; Gonzalez-Elipe, A. R.; Borras, A. ACS Appl. Mater. Inter. 2015, 7, 2331-2339.

(11) Shan, Y.; Yang, Y.; Cao, Y.; Fu, C.; Huang, Z. Nanotechnology 2016, 27, 145502.

(12) Yao, J.; Quan, Y.; Gao, M.; Gao, R.; Chen, L.; Liu, Y.; Lang, J.; Shen, H.; Zhang, Y.; Yang, L.; Yang, J. J. Mater. Chem. C 2019, 7, 8199-8208.

(13) Tao, Q.; Li, S.; Ma, C.; Liu, K.; Zhang, Q. Dalton Trans. 2015, 44, 3447-3453.

(14) Rajkumar, P.; Sarma, B. K. Appl. Surf. Sci. 2020, 509, 144798.

(15) Wang, Y.; Zhang, M.; Yu, H.; Zuo, Y.; Gao, J.; He, G.; Sun, Z. Appl. Catal. B-Environ. 2019, 252, 174186.

(16) Zhou, W.; Yin, B. C.; Ye, B. C. Biosens. Bioelectron. 2017, 87, 187-194.

(17) Zhao, Y.; Sun, L.; Xi, M.; Feng, Q.; Jiang, C.; Fong, H. ACS Appl. Mater. Inter. 2014, 6, 5759-5767.

(18) Miura, M.; Ohkubo, T.; Sugawara, K.; Okuyama, N.; Otani, K. Anal. Sci. 2002, 18, 525-528.

(19) Li, Q.; Ji, G. Talanta 1990, 37, 937-940.

(20) Wang, J.; Wang, Y. L.; Pan, Y. H.; Feng, L.; Chen, D. M.; Liu, Z. L.; Peng, D. P.; Yuan, Z. H. Food Anal. Method. 2016, 9, 3407-3419.

(21) Arnhard, K.; Schmid, R.; Kobold, U.; Thiele, R. Anal. Bioanal. Chem. 2012, 403, 755-768.

(22) Yuan, Q.; Liao, Z.; Wang, F.; Zhang, H.; Guo, Y.; Li, R. J. Liq. Chromatogr. Rel. Technol. 2013, 36, 958-967.

(23) Wang, L.; Zhao, H.; Qiu, Y.; Zhou, Z. J. Chromatogr. A 2006, 1136, 99-105. 